\title{
Qualificação e formação docente: a interdisciplinaridade nas reuniões por área na politecnia
}

\author{
Qualification and teachers training: interdisciplinarity in the meetings \\ per area in polytechnic
}

\author{
Everton Bedin* \\ Universidade Federal do Rio Grande do Sul \\ José Claudio Del Pino** \\ Universidade Federal do Rio Grande do Sul
}

Resumo Este artigo tem por intuito apresentar, por meio de uma pesquisa etnográfica de cunho qualitativo, via uso da observação e de diário de bordo, como as reuniões por área de conhecimento entre os professores do Ensino Médio na politecnia podem favorecer a interdisciplinaridade, a qualificação e a valorização docente, a fim de maximizar o processo ensino-aprendizagem e minimizar os índices de repetência e evasão na educação básica do estado gaúcho. Averiguou-se que a ideia da interdisciplinaridade não pode ficar restrita a um processo interno às respectivas áreas, mas entre os componentes curriculares de outras ciências, tratando-se de um processo que instiga a investigação crítica e coletiva; um modo de reelaborar a metodologia para que o educando possa entender as diferentes ramificações do conhecimento como pressupostos aos eixos da politecnia.

PALAVRAS-CHAVE: Formação docente; Interdisciplinaridade; Ensino politécnico.

\begin{abstract}
This article is meant to present, through an ethnographic qualitative research, via the use of observation and logbook, how meetings of the knowledge area among high schoolteachers in polytechnic may favor interdisciplinarity, qualification and teacher appreciation, in order to maximize the process teaching-learning and minimize rates of repetition and dropout basic education in the Gaucho state. I was examined that the interdisciplinarity idea can't be restricted to an internal process to the respective areas, but among the curricular components of other sciences, in the case of a process instigate collective research and critical; a way of reframing the methodology so that the student can understand different branches of knowledge assumptions as to the axes of the polytechnic.
\end{abstract}

KEYWORDS: Teacher training; Interdisciplinarity; Polytechnic education. 


\section{Introdução}

A educação está passando por inúmeras dificuldades há muito tempo. Dentre elas se destacam a evasão e/ou reprovação dos estudantes, a insuficiência da infra -estrutura escolar, a exorbitante carga horária docente, a minimização à formação docente e a ausência de tempo para o planejamento pedagógico de forma interdisciplinar. Assim, pensando em maximizar e qualificar o processo de ensino-aprendizagem, quiçá nesta vertente de ações interdisciplinares, a fim de atender as necessidades do mundo do trabalho e formar sujeitos mais críticos, reflexivos e autônomos frente ao mundo do trabalho, a Secretaria Estadual da Educação do Rio Grande do Sul (SEDUC), tendo como fundamento as considerações sobre interdisciplinaridade da Lei de Diretrizes e Bases da Educação Nacional (LDBEN, 1996) e dos Parâmetros Curriculares Nacionais (PCN, 2000), desenvolveu, dentre muitos, um projeto educacional com o intuito de fazer do educando o agente principal na construção do próprio conhecimento, debruçando-se na formação integral, articulando os eixos: Cultura, Ciência, Tecnologia e Trabalho (SEDUC, 2011).

Para isto, a Secretaria de Educação do estado gaúcho arquitetou um documento-base, o qual foi intitulado Proposta Pedagógica para o Ensino Médio Politécnico e Educação Profissional Integrada ao Ensino Médio - 2011-2014 (SEDUC-RS, 2011) $)^{1}$, propondo a reestruturação curricular do Ensino Médio para ser implantada de forma gradual durante os anos de 2012 a 2014, a qual, acredita-se, está sendo realizada em todas as escolas do supracitado estado e é conhecida como politecnia.

A proposta da implementação do Ensino Médio Politécnico (Politecnia) na rede pública do estado do Rio Grande do Sul, adveio da constatação de que, pelas antigas ações e processos de escolarização do ensino médio, esta modalidade apresentava baixos índices de aprovação e permanência nas escolas ${ }^{2}$, como mostra o gráfico abaixo. Assim, a insistência de um quadro negro, que reflete índices elevados sobre o fracasso escolar, seja pela perda de recursos materiais ou humanos, e também a inópia de inserção ao mundo do trabalho, levou as políticas públicas a pensarem estratégias de ensino para melhorar tal situação, potencializando o número de estudantes com acesso às escolas e a qualificação da aprendizagem, através de uma instituição sintonizada com as pretensões da juventude atual.

Figura 1 - Taxas de aprovação, reprovação e abandono no Ensino Médio.

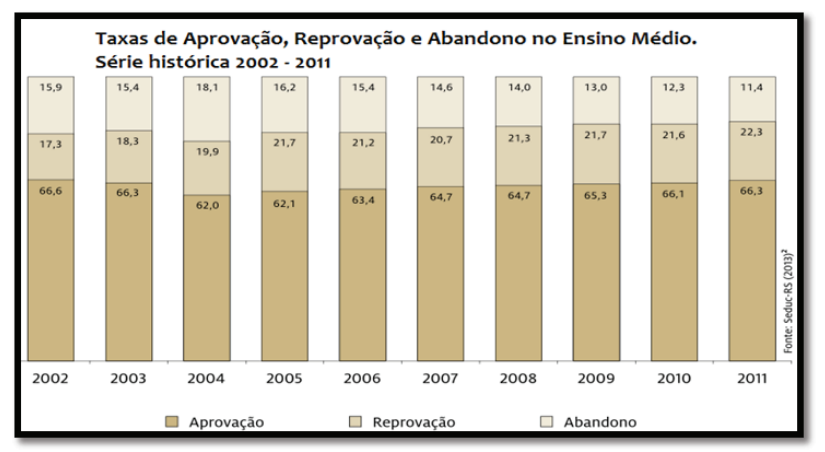


Essa reformulação de ensino para elevação nos índices de aprovação e permanência dos estudantes na rede pública de ensino no estado gaúcho, considerando a qualificação docente e a aprendizagem significava em suas linhas, exige, também, uma reestruturação curricular. Acredita-se que uma disposição flexível e dialógica, que enlace teoria e prática no trabalho com os conteúdos curriculares, seja a base contra as resistências discentes ao mundo escolar. Observa-se que há carência de um currículo que relacione o projeto de estudo ao projeto de vida dos estudantes. Nesse sentido, Gramsci ${ }^{3}$ (2006, p. 45) afirma que "a participação verdadeiramente ativa do aluno na escola só se concretiza se há ligação da escola com a vida, isto é, seu contexto”.

Desta forma, visando contribuir para a qualificação do processo de ensino-aprendizagem na politecnia, foi proposto como uma das maneiras possíveis para corroborar com este novo desenho, o entrelaçamento entre várias disciplinas que, no processo de reestruturação da educação nacional, aparecem agrupadas por áreas do conhecimento (Ciências da Natureza, Linguagens, Ciências Humanas e Matemática). A análise da figura abaixo mostra que a legislação vigente aponta para a adoção de programas de ensino voltados à integração dos saberes de forma interdisciplinar, isto é, a união das disciplinas pressiona para um trabalho interdisciplinar dentro da área de conhecimento, exigindo formação e qualificação docente.

\section{Imagem 2 - Reestruturação no Ensino Médio.}

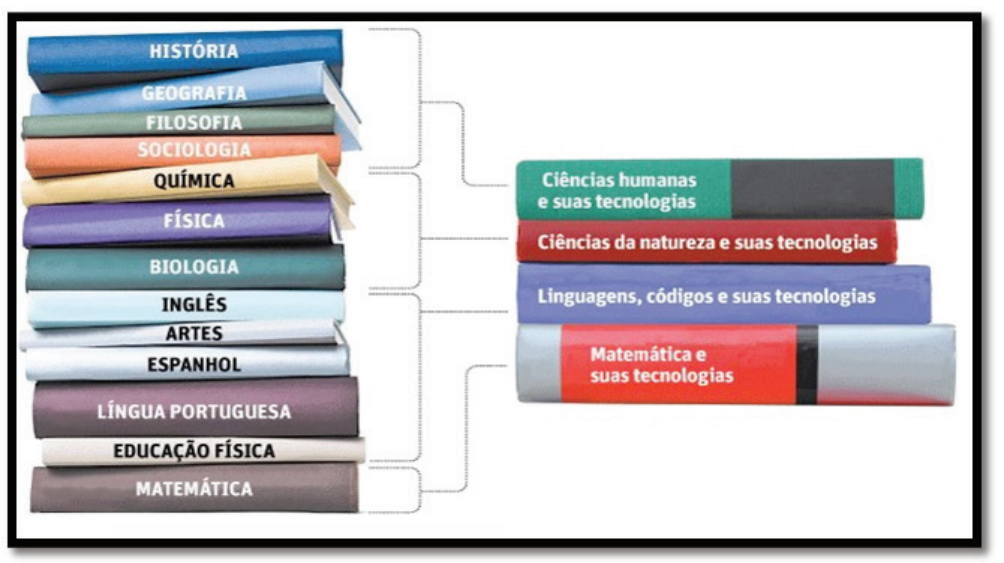

Destaca-se, ainda neste viés, que a politecnia, após a reestruturação, trouxe uma nova disciplina às escolas da rede pública de ensino: Seminário Integrado ${ }^{4}-\mathrm{SI}$. O tensionamento das áreas do conhecimentos dobra-se diante do Seminário Integrado, pois este passa a ser a ponte de origem e retorno dos saberes e da materialização dos trabalhos e produção de aprendizagem na politecnia. A disciplina, já supracitada, possui matriz na pesquisa, tornando-se cerne essencial para a construção do conhecimento conectado com o mundo do trabalho, constituindo-se como recurso pedagógico à produção do conhecimento de forma individual e coletiva, uma vez que permite ao estudante, agora considerado pesquisador, acesso à condição de criador, questionador e sujeito da construção do próprio saber. 
Portanto, nesta via de formação e emancipação do sujeito sociocultural, parece sagaz pensar na reestruturação do trabalho docente, buscando cada vez mais qualificação e formação, uma vez que adveio, junto com este projeto de politecnia, a reestruturação curricular que enfatiza a união de disciplinas por áreas de conhecimento, e a necessidade de reuniões para planejamento e programação de metodologias interdisciplinares. Desta forma, este artigo tem por intuito refletir sobre as concepções e perspectivas que emergem nas reuniões por área à luz da interdisciplinaridade. As reuniões, em nossa experiência, ocorrem na escola quinzenalmente, em prol da qualificação e formação docente.

\section{Aportes teóricos}

A reestruturação curricular proporcionou aos professores uma formação docente atualizada às vertentes da contextualização e da interdisciplinaridade, favorecendo o desenvolvimento e a ampliação das competências e das habilidades docentes, uma vez que a concepção de saberes no mundo cada vez mais globalizado exige a necessidade da proliferação e maximização destes aportes.

Nesta perspectiva, entende-se que a reestruturação trouxe, nas entrelinhas de seus objetivos, questões de cunho interdisciplinar explicitas no relacionamento que emerge na conexão entre as áreas do conhecimento, como pode-se perceber nas citações extraídas da Resolução no 2, do CNE, que define as Diretrizes Curriculares Nacionais para o Ensino Médio, e reafirma, também, vários posicionamentos já explicitados na Resolução no 4/CNE, definidora das Diretrizes Curriculares Nacionais Gerais para a Educação Básica:

Art. $8^{\circ}[\ldots] \S 1^{\circ} \mathrm{O}$ currículo deve contemplar as quatro áreas de conhecimento, com tratamento metodológico que evidencie a contextualização e a interdisciplinaridade ou outras formas de interação e articulação entre diferentes campos de saberes específicos. Art. 14 [...] VIII - os componentes curriculares que integram as áreas de conhecimento podem ser tratados ou como disciplinas, sempre de forma integrada, ou como unidades de estudos, módulos, atividades, práticas e projetos contextualizados e interdisciplinares ou diversamente articuladores de saberes, desenvolvimento transversal de temas ou outras formas de organização; [...] XIII - a interdisciplinaridade e a contextualização devem assegurar a transversalidade do conhecimento de diferentes componentes curriculares, propiciando a interlocução entre os saberes e os diferentes campos do conhecimento. (BRASIL, 2012).

Assim, a interlocução de disciplinas em áreas de conhecimento faz com que possam emergir, dependendo do trabalho docente e da qualificação do mesmo, pressupostos de interdisciplinaridade. Pois a mesma chegou ao Brasil no final da década de 60, desempenhando fortes influências na construção da Lei de Diretrizes e Bases (LDB) 5.692/71 e desde então, sua presença tem sido confinada no cenário educacional brasileiro, extrapolando-se à LDB 9.394/96 e aos Parâmetros Curriculares Nacionais (PCN), os quais apontam-na como um eixo integrador, que pode ser o objeto de conhecimento, um projeto de investigação, um plano de intervenção. Neste sentido, ela "deve partir da necessidade sentida pelas escolas, professores e estudantes de explicar, 
compreender, intervir, mudar, prever, algo que desafia uma disciplina isolada e atrai a atenção de mais de um olhar, talvez vários" (BRASIL, 2002, p. 88-89).

Nesta teia, a união das disciplinas em áreas de conhecimento traz a necessidade do planejamento em conjunto, isto é, faz com que os professores, antes executores de um planejamento individual e engavetado, que não demonstravMa atualização e/ ou trocas de saber e conhecimentos, passem a sentar juntos, quinzenalmente, para planejar e construir metodologias significativas, a fim de promover a ampliação do conhecimento científico, a interlocução com o contexto do estudante e a relação de uns com os outros. Esses fatores emergem nas reuniões por área do conhecimento, onde os professores usufruem de um tempo para relacionar a teoria e a prática no viés da pesquisa como princípio pedagógico.

De tal modo, buscam uma avaliação emancipatória por meio do planejamento coletivo, autônomo e crítico, pois compreendem que a mesma alicerça o reconhecimento de saberes sociais e culturais, além de buscar o princípio formativo e o relacionamento dos conteúdos com os eixos ciência, tecnologia, cultura e trabalho.

Assim, entende-se a necessidade de os professores diariamente buscarem a formação docente no viés da interdisciplinaridade e da contextualização dos saberes científicos, maximizando as discussões sobre amparadas em muitos autores (Fiorentini et al., 2001; Stodolsky, 1993; Monteiro, 2001) no âmbito de estudos que enfoquem a relação do professor com o conteúdo que ensina, proporcionando subsídios qualificados a complexidade e importância, pois são muitos os que, de certa forma, intervêm nesta formação, os quais perpassam a natureza epistemológica, como didática e organizacional, cultural e política, como aquelas relacionadas a própria área de conhecimento que se liga determinada disciplina.

Neste desenho, é sagaz pensar que muitos sentidos, curriculares ou políticos, são pensados e refletidos no viés das práticas interdisciplinares, uma vez que a organização e o desenvolvimento das atividades parte de um conjunto de professores; logo, as diferentes experiências e habilidades, assim como as múltiplas perspectivas, são capazes de favorecer ou inibir as atividades interdisciplinares. Portanto, as variações de compromissos e histórias, correlacionadas a múltiplos paradigmas pedagógicos, produzindo a hibridização de diferentes discursos aos discursos das políticas, podem derivar na origem de novos sentidos, necessariamente previstos nestas práticas (BALL, 1998; BALL; BOWE, 1998).

Assim, é possível compreender a interdisciplinaridade como "o princípio da máxima exploração das potencialidades de cada ciência, da compreensão dos seus limites, mas acima de tudo, é o princípio da diversidade e da criatividade" (ETGES, 1993, p.18). Todavia, é evidente que durante muito tempo, a coletividade de professores vem arquitetando muros intransponíveis entre os campos do saber e/ou áreas do conhecimento e, talvez, ao apostar na interdisciplinaridade como diz Santomé (1998), signifique apostar também em um tipo de pessoa mais "aberta, flexível, solidária, democrática e crítica" (p. 45). 
Nesta perspectiva, percebe-se claramente a necessidade de um professor democrático e atualizado ao campo do saber, uma vez que a integração da interdisciplinaridade se apresenta como o remédio mais adequado à cancerização ou à patologia geral do saber. Em outras palavras, a interdisciplinaridade, quiçá, pode ser caracterizada pela intensidade das trocas entre os professores que compõem as áreas de conhecimento e pelo grau de integração real das disciplinas no interior de um mesmo projeto de pesquisa (JAPIASSU, 1976, p.30).

Compete ressaltar, ainda, que a interdisciplinaridade é baseada, antes de tudo, na relação entre sujeitos, o que implica nos problemas contidos em todas as relações interpessoais, afinal, Fazenda (2001, pp. 11-12), esclarece que "a interdisciplinaridade pauta-se numa ação em movimento" uma prática que exige "humildade, coerência, espera, respeito e desapego", nos remetendo a noção da práxis e também ao trabalho coletivo, ou seja, não existe prática interdisciplinar isolada.

Assim, corrobora-se com Vilela e Mendes (2003) quando entende-se que:

A interdisciplinaridade é considerada uma inter-relação e interação das disciplinas a fim de atingir um objetivo comum. Nesse caso, ocorre uma unificação conceitual dos métodos e estruturas em que as potencialidades das disciplinas são exploradas e ampliadas. Estabelece-se uma interdependência entre as disciplinas, busca-se o diálogo com outras formas de conhecimento e com outras metodologias, com objetivo de construir um novo conhecimento. Dessa maneira a interdisciplinaridade se apresenta como resposta à diversidade, à complexidade e à dinâmica do mundo atual. (p. 529).

Diante do exposto, cabe ressalvar que a interdisciplinaridade é considerada uma inter-relação e interação das disciplinas com o princípio de atingir um objetivo comum e que, a partir da relação estabelecida entre elas, o estudante possa ressignificar seus saberes e ampliar seus conhecimentos científicos, favorecendo a unificação conceitual dos métodos e composições em que as potencialidades das disciplinas são exploradas e ampliadas na socialização e contextualização com o cotidiano.

Neste viés, se estabelece uma interdependência entre as disciplinas, buscando a valorização e a qualificação na formação dos professores em prol do diálogo com outras formas de conhecimento e com outras metodologias, com objetivo de construir um novo conhecimento mais abrangente, científico e respeitável. Dessa maneira, pode-se pensar que a interdisciplinaridade se apresenta como resposta à diversidade, à complexidade e à dinâmica do mundo atual (Vilela e Mendes, 2003, p. 529), pois a interdisciplinaridade ultrapassa as barreiras do conhecimento, tornando-se intercâmbio mútuo e integração recíproca entre as várias ciências.

Do mesmo modo, a interdisciplinaridade torna o conhecimento construído na relação com o outro, uma cadeia de ideias atomisticamente formada a partir do registro científico-interdisciplinar dos fatos e se reduz a uma simples cópia do real; favorece a interatividade professor-aluno e a conexão de teias abertas que formam a trama das relações; envolve a participação colaborativa, bidirecional e dialógica, pressupondo a compreensão de conhecimento como algo uniformizado; e, dentre outras 
ações, abre espaço à conexão e integração de várias linguagens, códigos e símbolos, favorecendo o mecanismos de participação e descentralização nos processos de ensino e de aprendizagem.

\section{Referencial metodológico}

Buscando alcançar o objetivo do presente artigo e considerando as reuniões por área do conhecimento como momentos que favorecem a construção de metodologias docentes, a qualificação e a formação dos professores sobre atividades de forma interdisciplinar, sobre a ótica de uma pesquisa etnográfica de cunho qualitativo, buscou-se intensificar a pesquisa com a coleta de dados via uso da observação e, automaticamente, diário de bordo. A pesquisa etnográfica, na visão de André (1995, p. 28) é chamada de participante porque "parte do princípio de que o pesquisador tem sempre um grau de interação com a situação estudada, afetando-a e sendo por ela afetado".

Assim, a pesquisa assume carater qualitativo na medida em que o pesquisador não parte de um esquema teórico fechado, que limite suas interpretações e impeça a descoberta de novas relações, pois, para Bodgan e Biklen (1994), é conhecida como:

[...]descritiva, onde os dados recolhidos são em forma de palavras e não de números. Os resultados escritos da investigação contém citações feitas com base nos dados para ilustrar e substanciar a apresentação $[. .$.$] a abordagem da pesquisa qualitativa exige que o mun-$ do seja examinado com a ideia de que nada é trivial, que tudo tem potencial para constituir uma pista que nos permita estabelecer uma compreensão esclarecedora do nosso objeto de estudo. (BODGAN; BIKLEN, 1994, p. 48-49).

Para tanto, fez-se necessário construir um espaço-tempo que contemplasse, ao mesmo tempo, as dimensões relativas à formação humana individual de cada professor e as extensões científico-tecnológicas da sala de aula, e acompanhar as diferentes reuniões em diferentes tempos, sem interferir no diálogo que emergia entre os professores e no tempo por eles já estipulado. Neste desenho, entende-se que as reuniões apresentavam-se com durabilidade de quatro horas, ocorrendo em espaços e datas diferentes, uma vez que os professores se reuniam por área de conhecimento para planejamento e avaliação das atividades.

Por fim, cabe ressaltar que a interpretação e análise dos dados realizados e esboçados abaixo foram efetivadas pelo pesquisador responsável pelo trabalho, isto é, a análise parte do ponto de vista deste pesquisador, portanto qualquer outra interpretação ou análise pode apresentar outros resultados. Da mesma forma, reflete-se que estes resultados são extensíveis à realidade do corpo docente do Ensino Médio Politécnico da determinada escola, não a todos os professores existentes naquela instituição, subentendendo-se que os sujeitos da pesquisa, na qual se deu a aplicação da observação, é tida como uma população de amostra do estado, mas totalidade naquela escola sobre o eixo politecnia.

Neste viés, destaca-se que a pesquisa desenhou-se com a participação de doze professores, sendo 3 da área de Ciências da Natureza, 3 da área de Ciências Hu- 
manas, 1 da Matemática e 5 da área de Linguagens. Destaca-se que o professor da área de Matemática desenvolve seu planejamento junto aos professores da área de Linguagem, pois, segundo o mesmo, sente maior afinidade e segurança com estes professores, isto é, a amizade de anos atrás em relação aos sujeitos da área das Linguagens faz com que o professor da matemática desenvolva seus trabalhos atrelados a eles. Entretanto, destaca-se que este processo não minimiza a interdisciplinaridade da matemática com as demais áreas, pelo contrário, favorece na união da mesma à luz das linguagens.

As reuniões que foram observadas ocorreram quinzenalmente por cerca de 4 horas, todas em turno contrário à carga horária dos professores, isto é, no momento em que os mesmos não estavam trabalhando na escola, sendo que os professores de uma mesma área se encontravam para planejar, sem a necessidade da presença da outra área.

\section{Resultados e discussões}

A coleta de dados basicamente ocorreu sobre a ação da observação, a qual trouxe subsídios ricos e interessantes, pois demonstrou como o grupo de professores desenvolve o trabalho pedagógico, buscando um trabalho coletivo e íntegro, almejando, na medida do possível, estabelecer relações dinâmicas e dialéticas entre os conteúdos que fundam as diferentes disciplinas, reconstituindo-se na totalidade das áreas.

Desta forma, entende-se que os professores, no viés das áreas do conhecimento, devem exercer atividades para expressar o potencial de integração e interlocução dos conteúdos disciplinares, isto é, saberes científicos aos saberes do senso comum, ampliando o diálogo entre os componentes curriculares e o contexto dos estudantes, com consequências perceptíveis e transformadoras da sociedade e da cultura escolar. Trata-se, deste modo, de um trabalho desenvolvido na conexão e socialização entre as áreas do conhecimento, especificamente nas reuniões, pois exige uma organização que tem a interdisciplinaridade como princípio ativo nos processos de ensino e aprendizagem.

Destaca-se, ainda, que a ideia da interdisciplinaridade não pode ficar restrita a um processo interno às respectivas áreas, mas entre os componentes curriculares de outras áreas. Para isto, o professor, por meio de seu trabalho pedagógico, deve ocupar-se, junto aos conceitos, as razões, os problemas, as necessidades e as dúvidas que constituem o contexto de produção de um conhecimento, isto é, relacionar-se com o estudante para instigar a ação da curiosidade, do pensamento e da reflexão, a fim de averiguar as atividades socioculturais para a conexão com o científico, pois a interdisciplinaridade torna-se mais do que um método, e sim uma necessidade à luz da aprendizagem (BRASIL, 2013, p. 15).

Pode-se perceber, neste desenho, que o novo currículo estabelecido na escola, de forma integrada e organizada, constitui o conhecimento e desenvolve o processo de ensino-aprendizagem de forma interdisciplinar buscando maneiras e formas em que os conceitos sejam apreendidos como sistema de relações de uma totalidade concreta e, do mesmo modo, que sejam ressignificados na realidade e cultura de cada educando. 


\begin{abstract}
Assentados sobre uma base ético-política e sobre o princípio da interdisciplinaridade, o Currículo, bem como suas dimensões especificamente epistemológica e metodológica, pode mobilizar intensamente os alunos, assim como os diversos recursos didáticos disponíveis e/ou construídos coletivamente. Pressupomos, com isto, a possibilidade de se dinamizar o processo de ensino-aprendizagem numa perspectiva dialética, em que o conhecimento é compreendido e apreendido como construções histórico-sociais e sua apreensão reconhecida pelos estudantes como necessária para a compreensão e eventual superação dos problemas identificados e reconhecidos como relevantes pela comunidade. (SEDUC, 2013, p. 41).
\end{abstract}

Neste meio, essas reuniões apresentam uma forma diferente de conversação e planejamento; elas correspondem a uma forma evolutiva de produzir material e conhecimento sobre um determinado assunto, pois quando os professores conversam sobre determinado conteúdo existe entrosamento de ideias e saberes, o que acaba por enriquecer determinada temática.

Deste modo, cogita-se que o trabalho que se estabelece na teia da área, através dos diálogos nas reuniões, fecunda-se em um eixo para evidenciar, na sala de aula, as razões, os problemas, as necessidades e as dúvidas que constituem o contexto de produção de conhecimento. Entende-se que a apreensão de informações na sua forma mais elaborada permite compreender os fundamentos prévios que levam ao estágio atual de compreensão e conhecimento em cada área, pois

[...] o trabalho interdisciplinar se apresenta como uma necessidade imperativa pela simples razão de que a parte que isolamos ou arrancamos do contexto originário do real para poder ser explicada efetivamente, isto é, revelar no plano do pensamento e do conhecimento as determinações que assim a constituem, enquanto parte, tem que ser explicitada na integridade das características e qualidades da totalidade. É justamente o exercício de responder a esta necessidade que o trabalho interdisciplinar se apresenta como um problema crucial, tanto na produção do conhecimento quanto nos processos educativos e de ensino. (FRIGOTTO, 2008, p. 33).

Destaca-se, ainda, que o trabalho desenvolvido na área de conhecimento apresenta uma organização formal de múltiplos saberes, isto é, não há perda de referencial na área e os conceitos passam a ser relacionados de forma íntegra, não só interdisciplinarmente, mas também intradisciplinarmente ${ }^{5}$. Entende-se que estes processos contribuem para a apreensão do processo histórico-social da produção de conhecimento. Nesta ótica, a interdisciplinaridade não é algo artificial, nem pode aparecer superficialmente no planejamento entre as disciplinas, mas uma necessidade que deve estar presente em todo o trabalho docente.

Assim, de acordo com Santomé (1998, p. 45) "ressurge com maior força um discurso que justifica a necessidade de reorganizar e reagrupar os âmbitos do saber para não perder a relevância e a significação dos problemas a detectar, pesquisar, intervir e solucionar". 
O currículo globalizado e interdisciplinar converte-se assim em uma categoria 'guarda-chuva' capaz de agrupar uma ampla variedade de práticas educacionais desenvolvidas nas salas de aula, e é um exemplo significativo do interesse em analisar a forma mais adequada de contribuir para melhorar os processos de ensino e aprendizagem. (SANTOMÉ, 1998, p. 27).

Portanto, entende-se que a ideia central é a dialogicidade, a qual emerge nas reuniões e, sem dúvida, apresenta-se como orientação pertinente e útil à formação e qualificação docente, pois é neste momento que os professores constroem e se reconstroem com o auxílio do outro, situando-se no conhecimento científico e nas práticas sociais. $\mathrm{Na}$ verdade, acredita-se que o diálogo tem se tornado, dentre muitos fatores com a inserção da politecnia nas escolas gaúchas, uma estratégia de análise da realidade escolar pelos educadores com base no conhecimento sistematizado de forma interdisciplinar.

Nesta teia, o trabalho que os professores desenvolvem parte da compreensão de que não existe receita pronta para a prática pedagógica interdisciplinar e de que não se pode adquirir uma concepção mais ampla a qual não seja construída pelo próprio conjunto de professores. Sendo assim, os professores compreendem que é na própria reflexão e reelaboração da concepção do trabalho interdisciplinar para a formação humana que o educando pode atribuir significado para seu contexto. Destarte, entende-se que os docentes, na convivência com os sujeitos envolvidos no processo educativo, podemos reconstruir a relação do fazer pedagógico interdisciplinar a partir de uma concepção mais ampla, atribuindo sentido e significado para a própria ação educativa.

Trata-se, portanto, de um processo que instiga a investigação crítica e coletiva, um modo de reelaborar a metodologia para que o educando possa entender as diferentes ramificações do conhecimento como pressupostos ao trabalho, uma vez que a interdisciplinaridade, assim como a contextualização, deve se aportar no fundamento epistemológico da relação entre parte e totalidade na produção da ciência e nos processos de ensino e aprendizagem. Especificamente, a dialogicidade, por meio da contextualização, é forma de orientar conexa e útil à formação integrada do sujeito, para além de situar o conhecimento científico em práticas sociais vividas. Tornando-se uma tática de análise da realidade social pelos educandos com base no conhecimento sistematizado das áreas; logo, um processo que provoca a investigação permanente e a curiosidade coletiva frente ao papel que deve cumprir a escola.

\section{Considerações finais}

A inserção da politecnia nas escolas gaúchas, sem discussão ou críticas sobre o modo como a mesma foi implementada, tem demonstrado avanços sobre a maneira com que os professores buscam planejar e desenvolver suas aulas, assim como avaliar, entender e refletir sobre a aprendizagem do estudante. De tal modo, pode-se intuir que os professores, ao longo das reuniões por área e com o passar do tempo, acabam por desenvolver atitudes de criticidade e autonomia, além de competências e habilidades a partir da adoção de métodos e técnicas viáveis para a melhoria do ensino-aprendizagem. 
Pode-se averiguar que, na relação com o outro que se estabelece nas reuniões por área, emergem diálogos e percepções sobre a interdisciplinaridade no trabalho docente, pois temáticas, ações e processos sobre a metodologia surgem com um respaldo de mediação integral e coletividade, atrelando desafios, reflexões, observações e construção de novas práticas. Miranda (2012, p. 118), neste sentido, afirma que o trabalho interdisciplinar e contextualizado "requer participação, cooperação e interação entre os participantes". Em outras palavras, os encontros que ocorrem mensalmente nas reuniões por área apontam para profissionais mais flexíveis e competentes às mudanças tecnológicas decorrentes da dinamicidade contemporânea, assim como para o processo de complementação da formação pelo trabalho interdisciplinar e pela aquisição de conhecimento por meio da socialização de ideias e concepções.

Assim, entende-se que cada componente curricular pode contribuir na compreensão da complexidade para a emersão da interdisciplinaridade, já que nenhum componente curricular consegue explicar tudo sozinho e, ao mesmo tempo, cada área do conhecimento se beneficia ao incorporar a si mesma um conhecimento mais vasto do que o restrito em sua fronteira. Neste desenho, o professor, mais do que um transmissor de conteúdos escolarizados, aprende e desenvolve a ação de articulador, instigando os estudantes na busca por relações entre os saberes científicos com o mundo e com o conhecimento que certamente, na era da conexão em rede, não está localizado em uma única fonte.

Por fim, cabe destacar que as reuniões possibilitam aos professores uma forma diferenciada de trabalhar, a qual confere aos estudantes desenvoltura na escrita, na participação e na inter-relação dos conhecimentos disciplinares, contribuindo para a formação da autonomia, da criticidade e da coletividade. Do mesmo modo, torna-se pertinente lembrar que na teia interdisciplinar privilegiam-se momentos de aprendizagem que corroboram na distinção progressiva, na reconciliação integradora (AUSUBEL, 1978) e na interação social (VYGOTSKY, 2007).

Ressalva-se que as atividades integradas desenvolvem ações que impulsionam a formação discente. Seja por meio da leitura e discussão de textos, seja pela realização de atividades experimentais ou pela realização de visitas orientadas na disciplina de Seminário Integrado, as quais ocorrem de forma ativa e reflexiva no que tange à complexidade dos conteúdos relacionados aos eixos da politecnia. Assim, considerar o contexto no desenvolvimento do ensino e da aprendizagem exige não só integrar componentes curriculares, mas também criar espaços e vivências que permitam aos sujeitos à expressão de seus saberes e o desenvolvimento de suas identidades socioculturais.

\section{Referências}

ANDRÉ, M. Etnografia da prática escolar. 15. ed. Campinas: Papirus, 1995.

AUSUBEL, D. P. Psicologia educativa: un punto de vista cognoscitivo. México: Trillas, 1978.

AZEVEDO, J. C.; REIS, J. T. (Org.). Reestruturação do ensino médio: pressupostos teóricos e desafios da prática. 1. ed.. São Paulo: Fundação Santillana, 2013.

BALL, S. Cidadania global, consumo e política educacional. In: SILVA, L. H. (Org.). A escola cidadã no contexto da globalização. Petrópolis: Vozes, 1998. p. 121-137. 
BALL, S. J.; BOWE, R. El currículum nacional y su "puesta en práctica”: el papel de los departamentos de materias o asignaturas. Revista de Estudios del Curriculum, v. 1, n. 2, p. 105-131, 1998.

BODGAN, R. C.; BIKLEN, S. K. Investigação qualitativa em educação: uma introdução à teoria e aos métodos. Porto: Porto, 1994.

BRASIL. Conselho Nacional de Educação (CNE). Resolução no 2, de 30 de Janeiro de 2012 sobre Diretrizes Curriculares Nacionais para o Ensino Médio. Diário Oficial d União, Brasília, DF, 31 de janeiro de 2012, Seção 1, p. 20.

. Lei de Diretrizes e Bases da Educação Nacional - LEI n. 5.692/71 de 11 de agosto. Congresso Nacional - Brasil - Brasília, 1971.

. Ministério da Educação e Cultura. Secretaria de Educação do Ensino Médio. Parâmetros Curriculares Nacionais: Bases Legais. Brasília, 2000.

. Ministério da Educação e Cultura. Secretaria de Educação do Ensino Médio. Parâmetros Curriculares Nacionais + $(\mathrm{PCN}+)$. Ciências da Natureza e suas Tecnologias. Ministério da Educação. Secretaria da Educação Média e Tecnológica - Brasil - Brasília, 2002.

. Lei de Diretrizes e Bases da Educação Nacional - LDB no 9.394/96 de 20 de dezembro. Congresso Nacional - Brasil - Brasília, 1996.

. Secretaria de Educação Básica. Formação de professores do ensino médio, etapa I caderno IV: áreas de conhecimento e integração curricular / Ministério da Educação, Secretaria de Educação Básica; [autores: Marise Nogueira Ramos, Denise de Freitas, Alice Helena Campos Pierson]. - Curitiba: UFPR/Setor de Educação, 2013. 47p.

ETGES, N. J. Produção do conhecimento e interdisciplinaridade. Educação \& Realidade. Porto Alegre: Fac. Educ./UFRGS, v. 18, n. 2, p. 73-82, jul./dez., 1993.

FAZENDA, I. C. A. Dicionário em construção: interdisciplinaridade. São Paulo: Cortez, 2001.

FIORENTINI, D.; SOUZA, Jr.; MELO, G. F. A. de. Saberes docentes: um desafio para os acadêmicos e práticos. In: GERALDI, C. M. G.; FIORENTINI, D.; PEREIRA, E. M. de A. (Org.). Cartografias do trabalho docente: professor (a) pesquisador (a). Campinas: Mercado de Letras/ALB, 2001. p. 307-335.

FRIGOTTO, G. A interdisciplinaridade como necessidade e como problema nas ciências sociais. Revista do Centro de Educação e Letras, 10(1), 41-62. Foz do Iguaçu: Unioeste, 2008.

GRAMSCI, A. Cadernos do Cárcere: os intelectuais. O princípio educativo. Jornalismo. v. 2. 4. ed.. Rio de Janeiro: Civilização Brasileira, 2006.

JMONTEIRO, A. M. F. da C. Professores entre saberes e práticas. Educação \& Sociedade, São Paulo, v. 22, n. 74, p. 121-142, abr. 2001.

RIO GRANDE DO SUL. Proposta pedagógica para o Ensino Médio Politécnico e Educação Profissional integrada ao Ensino Médio. Porto Alegre. 2011. Disponível em: <http://www. educacao.rs.gov.br/dados/ens_med_proposta.pdf>.Acesso em: 10 out. 2014.

SANTOMÉ, J. T. Globalização e Interdisciplinaridade: o currículo integrado. Porto Alegre: Artes Médicas, 1998.

STODOLSKY, S. S. A framework for subject matter comparisons in high schools. Teaching and Teacher Education, v. 9, n. 4, p. 333-346, 1993.

VILELA, E. M.; MENDES, I.J.M. Interdisciplinaridade e saúde: estudo bibliográfico. Revista Latino-Americana de Enfermagem, v. 11 n. 4. Ribeirão Preto. 2003.

VYGOTSKY, L. S. A formação social da mente. 7. ed. São Paulo: Martins Fontes, 2007. 


\section{Notas}

${ }^{1}$ Além dos textos normativos da educação nacional, o referido documento-base foi construído apoiando-se nas proposições teóricas de Antonio Gramsci, Karel Kosik, Acácia Kuenzer, Paulo Freire, Dermeval Saviani, Gaudêncio Frigotto, Carlos Rodrigues Brandão, Ivani Fazenda, Domingos Leite Lima Filho, Maria Ciavatta, Marise Ramos, Lucília Machado e Ana Maria Saul (SEDUC-RS, 2011).

${ }^{2}$ Os dados concretos que se tem em registros periódicos sobre os resultados quantitativos dessa etapa da Educação Básica na rede estadual são de 1975 em diante, com variações pontuais em sua metodologia de coleta e organização (AZEVEDO; REIS, 2013. p. 32).

${ }^{3}$ Gramsci (2006, p. 39) afirma que "o estudo e o aprendizado dos métodos criativos na ciência e na vida devem começar nesta última fase da escola, não devendo mais ser um monopólio da universidade ou ser deixado ao acaso da vida prática; esta fase escolar já deve contribuir para desenvolver o elemento da responsabilidade autônoma nos indivíduos, com base na ideia de uma escola criadora".

${ }^{4}$ O SI é um espaço-tempo presente na organização curricular do Ensino Médio Politécnico (EMP) (SEDUC-RS, 2011). É um espaço destinado à reflexão interdisciplinar sobre temas escolhidos a partir do diálogo docente-discente, proposto de acordo com os interesses de pesquisa e estudo a serem desenvolvidos. Nele é privilegiado o diálogo e a investigação de temáticas e conteúdos, proporcionando ao educando a complexificação de seus saberes com vistas à produção de aprendizagens significativas e duradouras no âmbito desse nível de ensino, articulando as categorias: trabalho, ciência, tecnologia e cultura. Isso abre possibilidades para que os discentes elaborem seu projeto de vida em sintonia com os campos de conhecimento pertinentes e os desafios da vida real.

${ }^{5}$ Assume-se essa ideia para o momento em que o professor consegue fazer conexões dentro de sua disciplina, navegando assincronamente por todos os eixos que a fundam no Ensino Médio Politécnico, isto é, um processo que caracteriza o interior de uma única disciplina.

* Professor doutor da Escola Estadual de Ensino Médio Antônio Stella, Ibiraiaras, Rio Grande do Sul, Brasil.

** Professor doutor da Universidade Federal do Rio Grande do Sul, Porto Alegre, Rio Grande do Sul, Brasil.

\section{Correspondência}

Everton Bedin - Escola Estadual de Ensino Médio Antônio Stella, EEEM Antônio Stella. Rua Longino Zacarias Guadagnin, Centro, CEP: 95305-000 - Ibiraiaras, Rio Grande do Sul - Brasil.

E-mail: bedin.everton@gmail.com - delpinojc@yahoo.com.br

Recebido em 11 de março de 2015

Aprovado em 12 de dezembro de 2015 
